\title{
SERS detection of DNA cancer with single- base mutation for KRAS-gene
}

\author{
T. Abdallah*, H. Awad, and H. Talaat \\ Physics Department, Faculty of Science, Ain Shams University, \\ Abbassia, Cairo, Egypt.
}

\begin{abstract}
We present a method based on surface enhanced Raman spectroscopy (SERS) to detect DNA KRAS-gene with single-base mutation. The KRAS gene belongs to the oncogenes class of genes. KRAS mutations cause normal cells to become cancerous. The detection utilizes DNA gene probes labeled by CY3 dye (as Raman marker) and plasmonic silver nanoparticles (Ag NPs) deposited on SERS substrates. SERS detect DNA via hybridization to the complementary DNA (target) sequences with single-base mutation. This SERS technique is a powerful tool and has a great potential gives both affectability and selectivity. Also, we utilized the Raman mapping to provide chemical information coupled with spatial information. The mapping image was obtained using scanning with three Raman bands over selected areas of the sample. The limit of detection (LOD) was accomplished down to a concentration $9 \mathrm{nM}$ after the addition of magnesium sulfate $\left(\mathrm{MgSO}_{4}\right)$ aggregated agent, causing hot spots of the aggregated $\mathrm{Ag}$ NPs.
\end{abstract}

\section{Keywords}

Surface enhanced Raman spectroscopy, Plasmonics, KRAS-gene, Cancer mutation

\section{C.A: tamerabdallah74@gmail.com}

Receive Date: 22 October 2021; Revise Date:5 November2021; Accept Date: 7 November 2021; Publish:8 November 2021 


\section{Introduction}

After discovering the double helix structure of deoxyribonucleic acid (DNA) in 1953, the identification and sequencing of the DNA molecules attracted attention ${ }^{[1]}$. The sequence of nucleic acid that varies from one living organism to another, pathogen or virus, offers experimental methods for recognizing and discriminating different diseases ${ }^{[2-4]}$. Therefore, the evolution of DNA-based diagnostics took place, including the DNA polymerase isolation, restriction fragment length polymorphism (RFLP), random amplified polymorphic DNA (RAPD), and the technique of polymerase chain reaction $(\mathrm{PCR})^{[5-7]}$. Cancer as an uncontrollable cell growth begins when changes in the genes take place, causing gene mutation.

Human DNA contains more than 20,000 genes, and when a portion of those genes is mutated, a wild cell multiplication happens to cause cancer. Those genes are then oncogenes, and KRAS is one of those oncogenes and occurs in $22 \%$ of all tumors ${ }^{[8-10]}$ analyzed (the highest among RAS isoforms). Traditional approaches to study gene mutations are PCR and DNA sequencing ${ }^{[11]}$. The sequencing technique is ideal for profiling long nucleic acid sequences; however, the significant expense and extensive stretch of investigation make it not suitable for single-base mutation detection. Though PCR and Sequencing are currently the standards for mutation screening of malignant tumors, scientists are starting to create intensification-free techniques for point mutation analysis. This way, Raman emission can be enhanced by utilizing specific metals that are in-tune with laser frequency, inclining toward an effect named Surface Plasmon Resonance (SPR) ${ }^{[12,13]}$. Using nanoparticles or nanostructures of a metal like gold or silver, analytes may come in legitimate vicinity to this SPR effect and lead to a dramatic amplification of Raman emission photons called surface enhanced Raman spectroscopy (SERS). SERS has become a powerful technique for cancer diagnoses ${ }^{[14-20]}$. Since it is offering amplification-free mutation detection with extremely high sensitivity down to single-molecule level ${ }^{[21-25]}$, by simply attaching the complementary DNA sequence probe with Raman marker dye onto metal nanoparticles and obtaining the distinct amplified Raman signatures of the Raman marker after hybridizing with a single base mutation, the mutated template could be 
directly identified ${ }^{[26]}$. The enhanced signal from the marker is due to $\mathrm{Ag}$ NPs are deposited in the proximity of the probe. These SERS sensors are easy to fabricate and low cost. In this work, we present an integrated method for detecting single nucleotide DNA cancer KRAS mutation with such a simplified procedure. The key to this method is the specific DNA sequence complementary probe, labeled with a Raman marker, in our case CY3 Dye.

\section{Experimental}

\subsection{Materials}

Samples utilized in this work are synthetic DNA templates, with a single-base mutation ( $\mathrm{C}$ changed to $\mathrm{A}$ ) and Raman marker (CY3 dye) labeled probes that were purchased from (Eurofins, Germany). For comparison, sequences of both normal (wild type) and mutated templates were used. The

wild type (WT) and mutated (MT) DNA samples with a labeled complementary probe for the mutated templates are shown in Table 1.

Table 1: DNA samples (KRAS exon2 gene from 5' to 3')

Wild type (WT) Template: TCTGAATTAGCTGTCGTAAGGCATCTTGCCTACGCCACCAGCTCCAACTACCACAAGTTTATATTCAG

Mutated (MT) Template: TCTGAATTAGCTGTCGTAAGGCATCTTGCCTACGCCACAAGCTCCAACTACCACAAGTTTATATTCAG MT Cy3 labeled Probe: TTGGAGCTTGTGGCGTAGGCA(CY3)

\subsection{Synthesis of silver nanospheres}

The amplification of the probe Dye Raman signal in the SERS is done by the increased plasmonic electromagnetic field of the silver nanoparticles (Ag NPs) participating in the SERS substrate. We synthesized Ag NPs using the chemical reduction method. First, all solutions of reacting materials were prepared in deionized water. In brief, $50 \mathrm{ml}$ of $0.001 \mathrm{M} \mathrm{AgNO} 3$ was heated to boil. Then $5 \mathrm{ml}$ of $1 \%$ trisodium citrate was added drop by drop to the boiling solution. During the process, solutions were blended enthusiastically and warmed until the change of color was evident (pale yellow). At that point, 

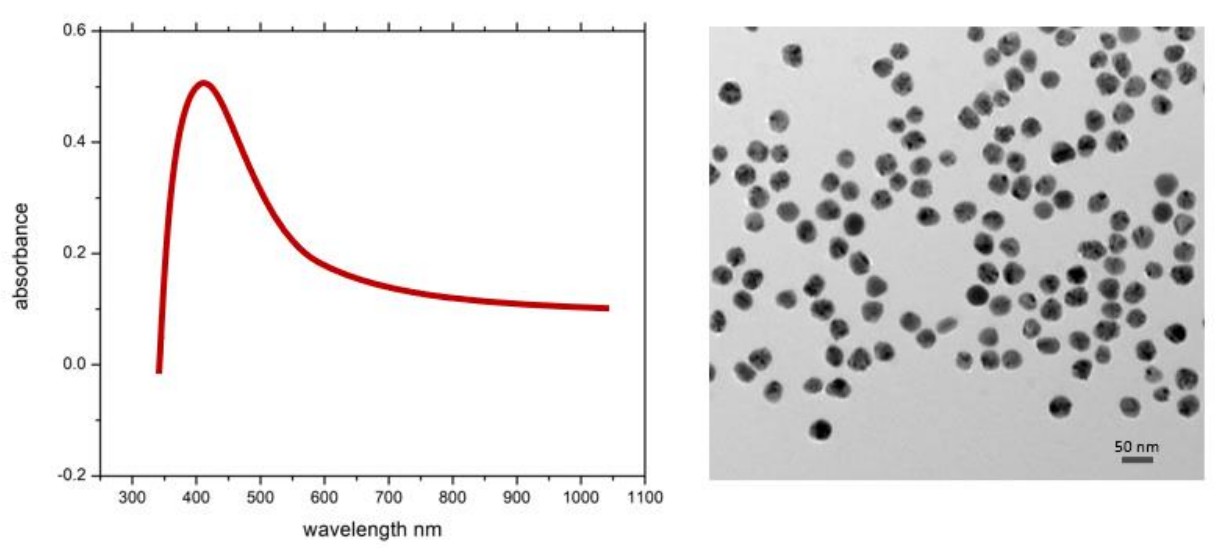

Figure 1 UV-Vis absorption spectrum and TEM image of Ag NPs

it was taken out from the heating plate and mixed until cooled to room temperature. $2 \mathrm{ml}$ silver colloid reduced by sodium citrate was centrifuged (5000 rpm, $10 \mathrm{~min}$ ), and the supernatant was removed. The final concentration of $\mathrm{Ag}$ nanoparticles in the concentrated colloid was about $23.55 \mathrm{nM}$, as determined using Beer-Lambert Law ${ }^{[27]}$.

Figure 1 shows the UV-Vis absorption spectrum and TEM image of synthesized Ag NPs obtained by reducing silver nitrate by trisodium citrate. The absorption peak was found at $410 \mathrm{~nm}$, which indicates the particle size of about $36 \mathrm{~nm}^{[28-30]}$.

\subsection{Fabrication of SERS substrate}

A multi-well glass slide was used as a substrate with ten wells, every $0.02 \mathrm{~cm}^{2}$. The procedure for sample preparation, their immobilization, and hybridization in the multi-wells are presented in Figure 2. The used configuration for differentiation between normal and mutated DNA templates can be described in four steps. First, surface modification of the wells with cationic polymer (polyethyleneimine PEI) was carried out (Step a). Next, DNA template immobilization (Step b). DNA hybridization with a complementary probe labeled with a Raman marker (Step c). Finally, SERS measurement for the Raman marker using Ag NPs was obtained (Step d). 


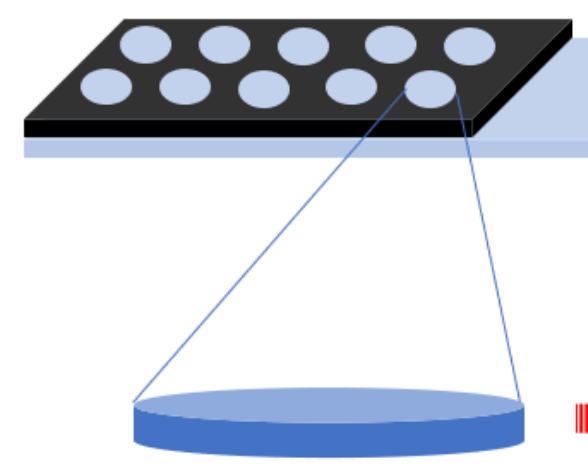

(a) PEl modified glass substrate

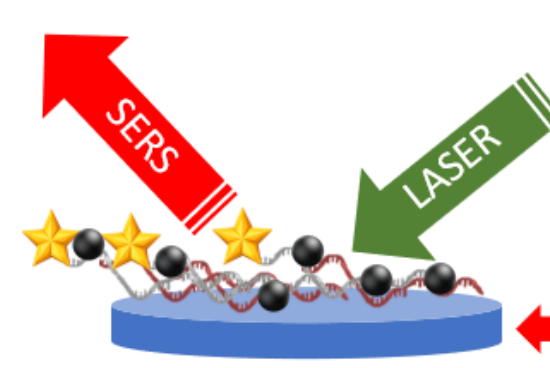

(d) SERS measurements of CY3 Dye

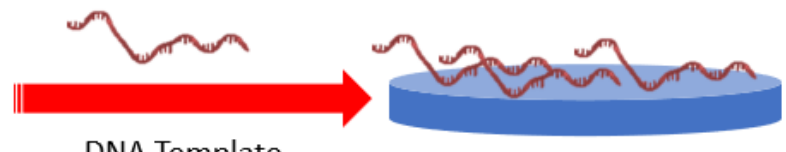

(b) Immobilized DNA Template

DNA Template

Ag Nanoparticles

Washing and adding Ag Nanoparticles

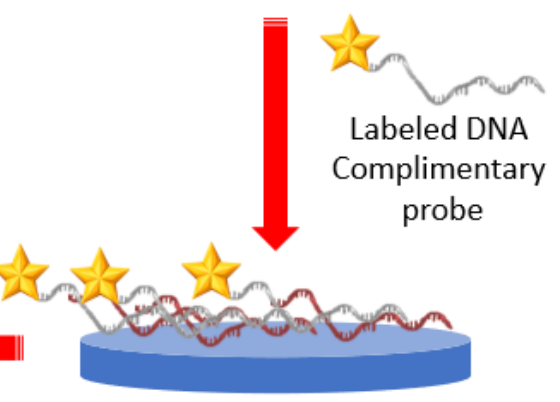
probe

(c) Hybridization process

Figure 2 Schematic representation for the hybridization process

\subsection{DNA immobilization}

DNA (normal and mutated) templates were immobilized inside the multi-wells substrate using polyethyleneimine (PEI) coating. This is done to achieve electrostatic adsorption. PEI is a polycationic polymer with a repeating unit

that contains a positively charged amine group. The electrostatic interaction between negatively charged phosphate groups of DNA and the positively charged glass modified surface affects the immobilization of the DNA. To test the immobilization, we use the following steps:

- $500 \mathrm{ng} / \mu \mathrm{l}$ DNA human genome was diluted in the same volume of $40 \%$ glycerol solution.

- Glass slide was coated by PEI.

- DNA droplets are pipetted on the surface

- Substrate was placed at $50{ }^{\circ} \mathrm{C}$ in the incubator overnight. 
- Ethidium Bromide dye binds to DNA by a van der walls force to stain the DNA.

- Substrate was washed by dipping in PBS for 15 mins, and then the slide is placed under a UV lamp.

Figure 3 Shows immobilized DNA stained with ethidium bromide under the UV lamp illumination.

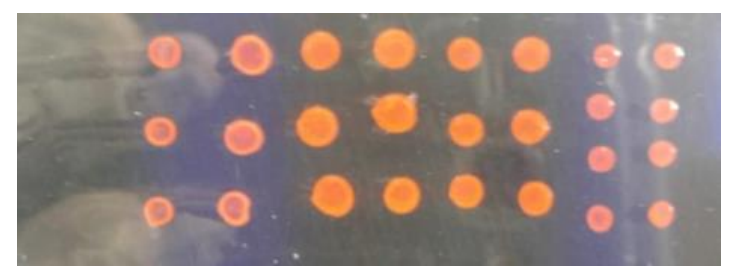

Figure 3 immobilized DNA stained with ethidium bromide under the UV lamp.

\subsection{DNA hybridization}

After testing the immobilization, we achieve the DNA hybridization using the following procedure:

- $0.04 \mathrm{~g} / \mathrm{ml}$ PEI solution was injected by a micro pipette in a freshly prepared substrate to fill the wells for $20 \mathrm{~min}$.

- The multi-wells substrate was washed with deionized water for 1 min, and the substrate was left to dry in air.

- $2 \mu \mathrm{l}$ drop of $10 \mu \mathrm{M}$ normal DNA template was placed inside each well on the PEI modified wells (the same was done for the mutated DNA template).

- The multi-wells substrate was incubated at $50{ }^{\circ} \mathrm{C}$ overnight.

To achieve high assay specificity, it is crucial to minimize the non-specific biomarker (labeled probe) adsorption. Therefore, we used egg albumin as a surface blocking reagent to block any space on the substrate not covered by DNA. 1\% egg albumin in PBS solution was injected into the wells and left for an hour at room temperature, and then the wells were washed with PBS for $1 \mathrm{~min}$. The probe complementary to the mutated DNA was prepared by dissolving in Saline Sodium Citrate (1x SSC), used as a hybridization buffer, to a final concentration of $0.16 \mu \mathrm{M}$. DNA hybridization of the probe to DNA is then carried out by injecting the DNA probe with $\mathrm{Cy} 3$ dye as a Raman marker into the wells. The substrate is then incubated at $50{ }^{\circ} \mathrm{C}$ overnight, 
then washed three times in $1 x$ SSC only to remove any un-attached DNA probes.

\section{Result and Discussion}

\subsection{SERS measurements}

SERS measurements were carried out for mutated and normal DNA template wells to detect the $\mathrm{Cy} 3$ molecules using the HORIBA Scientific Labram HR evolution machine. $2 \mu \mathrm{l}$ of concentrated Ag NPs were added to wells, both having mutated and normal DNA. A 532nm laser source was used with the 10x microscope lens. The acquisition time was $10 \mathrm{sec}$, and the grating used was 600 lines $/ \mathrm{mm}$. Figure 4 shows the obtained SERS spectra for (a) CY3 dye, (b) mutated DNA template (c) wild type (normal) DNA template. Cy3 Raman spectrum peaks for Raman marker are much more pronounced in the case of the mutated DNA template. This means that the Cy3 molecules have a significantly higher concentration in the area having mutated DNA template, indicating binding of the probes to the mutated template in a stable double strand. On the other hand, a trace amount of $\mathrm{Cy} 3$ was found in the case of a normal DNA template. In contrast, binding between the probes and the wild-type template results in much less stable double strands. The amount of mutated DNA detected was estimated for the number of DNA probes per laser spot area inside each well; the amount of DNA is found to be about 2 fmole.

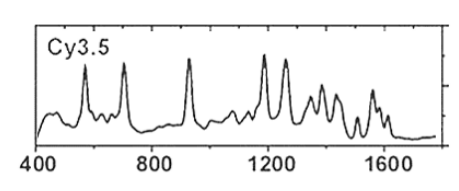

(a)

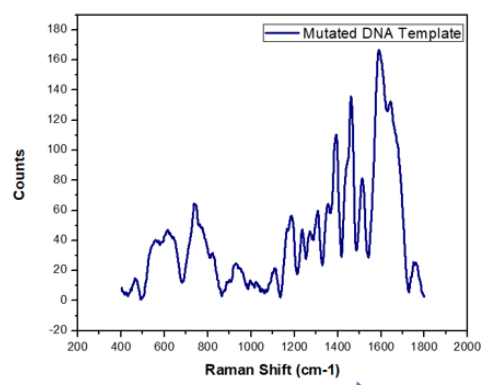

(b)

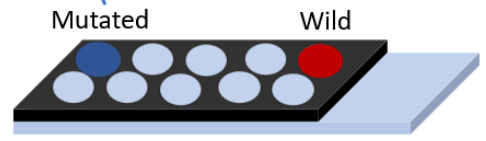

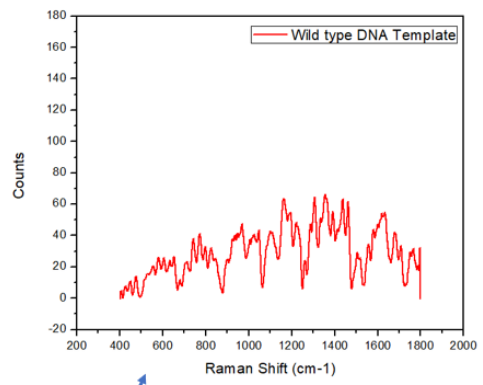

(c)

Figure 4 SERS measurement for mutated (a) CY3 Dye Raman Spectrum (b) Mutated DNA template SERS spectrum (c) Wild type DNA template SERS spectrum

The limit of detection (LOD) for the SERS method was determined by taking the SERS signal for eight solutions of labeled probes with varying 
concentrations, as shown in Figure 5. The concentrations of probes used were $10000,5000,2500,1250,625,313,156$, and $78.1 \mathrm{nM}$. The DNA concentration is correlated with the spectral feature peak intensity of the CY3 Raman band at $1470 \mathrm{~cm}^{-1} .2 \mu 1$ drop of these concentrated labeled probes are placed inside the multi-wells glass substrate let dry in air. A $2 \mathrm{ml}$ drop of concentrated Ag NPs (23.55 nM) is placed on the probe and let dry before SERS measurement. A linear regression line was drawn using the spectral peak of $\mathrm{Cy} 3$ located at $1470 \mathrm{~cm}-1$ (Figure 5). The LOD was obtained from the intensity versus concentration curve shown in Figure 6. The regression coefficient (R2) of the line was 0.96 . The limit of detection LOD was calculated by tripling the standard deviation (SD) then dividing by the slope $(L O D=3 S D / \text { slope })^{[31]}$ and was found to be about $14 \mathrm{nM}$.

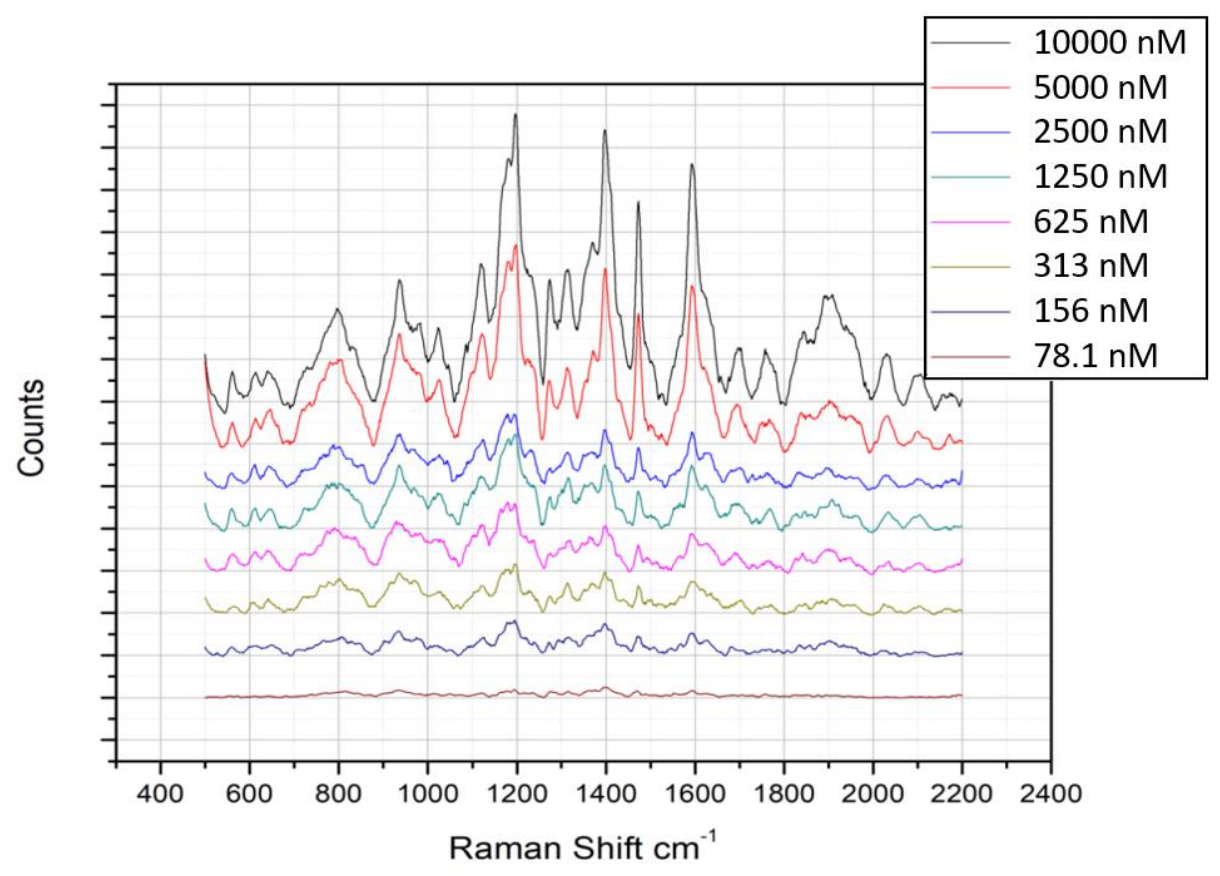

Figure 5 SERS spectra of the eight $\mathrm{Cy} 3$ labeled probes solutions with increasing concentrations. 


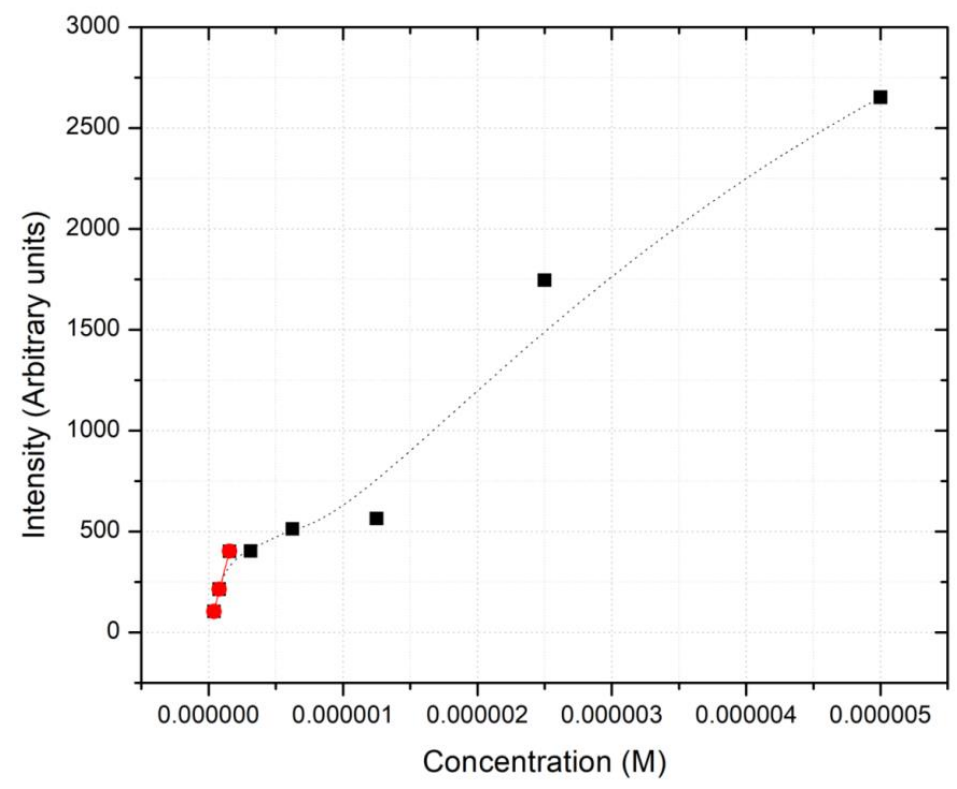

Figure 6 Linear regression line drawn by the peak intensities of Raman band at $1470 \mathrm{~cm}^{-1}$.

As opposed to Raman spectroscopy, which gives discrete chemical information at different positions within the sample, Raman mapping offers such chemical information combined with spatial information ${ }^{[2,33]}$. This is an invasive technique with high chemical specificity. In Raman mapping, the laser spot scans the examined sample area with preset step size and obtains total Raman spectra at each setpoint, then color images are obtained. This image is based on material composition with high sensitivity and resolution. Raman images in our case were obtained by selecting one Raman band of the CY3 dye and scan the over-determined area of the sample for this band. The scanned area was about $100 \times 100 \mu \mathrm{m}^{2}$, with a step of $10 \mu \mathrm{m}$ along the $\mathrm{X}$ and $\mathrm{Y}$ axes. Three Raman images were obtained using Raman bands at $560 \mathrm{~cm}^{-1}, 1470 \mathrm{~cm}^{-1}$, and $1590 \mathrm{~cm}^{-1}$. The band at $560 \mathrm{~cm}^{-1}$ is associated with the bending vibrations of the $\mathrm{C}-\mathrm{C}(\mathrm{CH} 3)-\mathrm{C}$ moieties. The strong band near $1470 \mathrm{~cm}^{-1}$ is attributed to the $\mathrm{CH} 3$ symmetric deformation in $\mathrm{Cy} 3$. The strong band at $1590 \mathrm{~cm}^{-1}$ is associated with $\mathrm{C}=\mathrm{N}$ stretching mode. The 2D-Raman images obtained for different Raman bands for mutated and wild type (normal) DNA templates after hybridization with the 
labeled mutated probe are shown in Figure 7. In the three-dimensional (3D) images, where the third dimension represents the SERS intensity of the selected Raman band line. The intensity of the mutated template is much higher than that of the normal one for the three-band lines. The low intensity of the wild type due to the inhomogeneity of the blocking layer allowing some binding of the probe with the PEI. Figure (7-d) shows the mean intensity of the Raman band line over the scanned area for the three bands.

\subsection{Effect of the aggregating agent}

To enhance the Raman signal, several approaches have been developed to increase the number of "hot spots" of Ag NPs, which leads to an increase in the chances to trap the DNA probe molecules in a "hot spot". This can improve the detection limit by adding aggregation agents ${ }^{[34,35]} .2 \mu \mathrm{L}$ drop of $0.01 \mathrm{M}$ magnesium sulfate $\left(\mathrm{MgSO}_{4}\right)$ was added to force the aggregation of the Ag NPs. The color of the colloids turns from yellow-green to chocolate immediately under such conditions. DNA probe concentration down to $9 \mathrm{nM}$ (one order of magnitude smaller than without aggregation agent) is detected.Figure 8 shows the Raman Spectrum for $9 \mathrm{nM}$ labeled probe after the addition of aggregated Ag NPs.

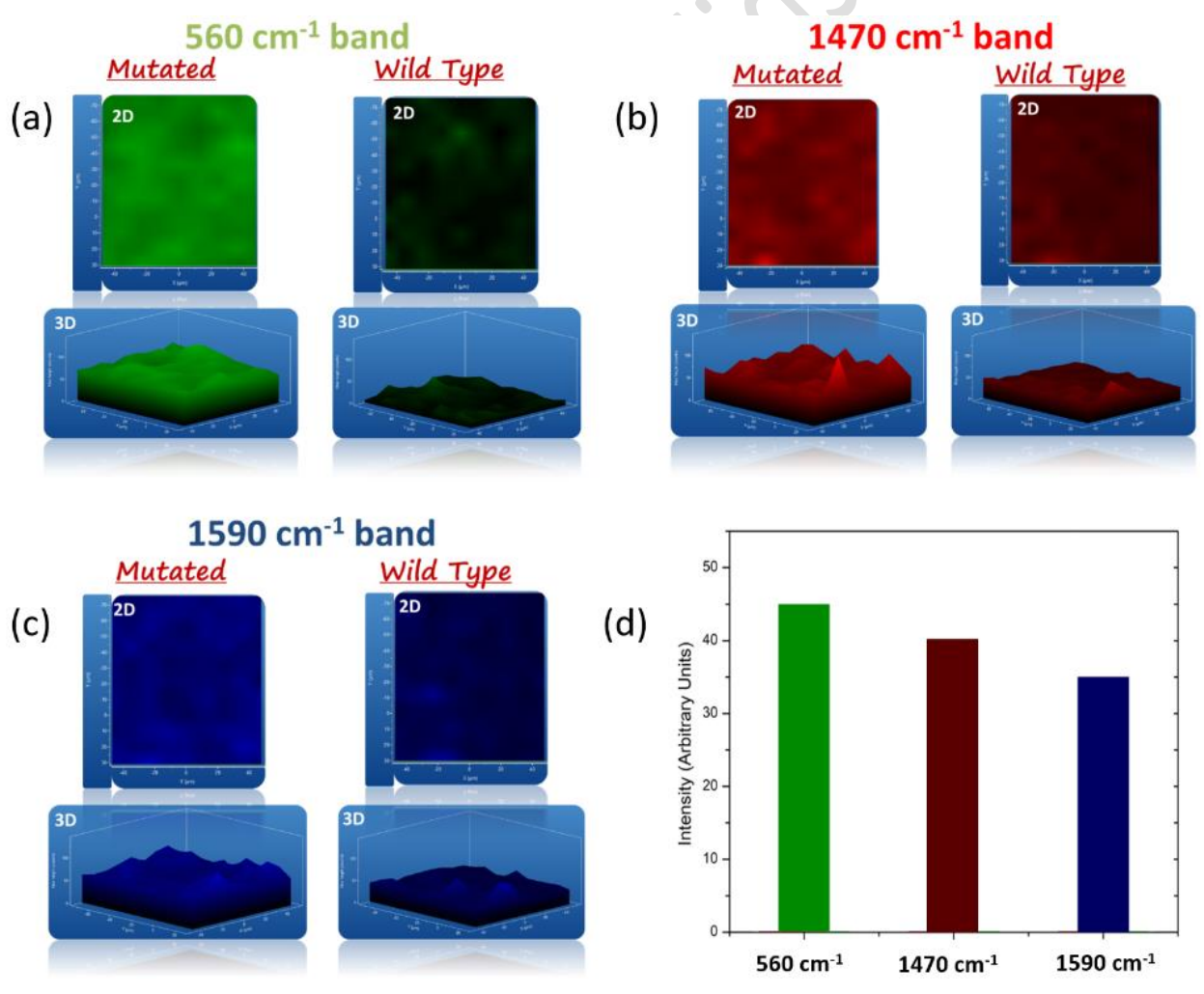

Figure 7 2D and 3D Raman maps for mutated and wild type (normal) DNA templates using (a) $560 \mathrm{~cm}^{-1}$ (b) $1470 \mathrm{~cm}^{-1}$ (c) $1590 \mathrm{~cm}^{-1}$ and (d) the intensities of the mutated

DNA. 


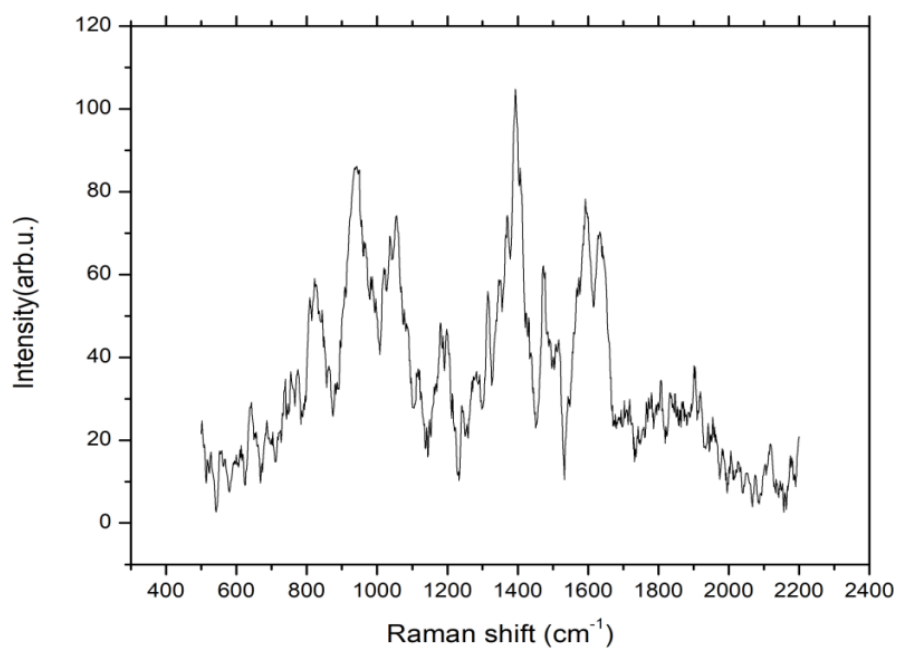

Figure 8 SERS spectrum for labeled DNA probes with $9 \mathrm{nM}$ concentration.

\section{Conclusion:}

Our experiment was committed to distinguishing single nucleotide DNA cancer mutations through a sensitive and explicit strategy offered by SERS, with minimal sample preparation and low cost to achieve early recognition of malignant growth. DNA concentration down to $9 \mathrm{nM}$ was accomplished utilizing hot spots to aggregated Ag NPs. SERS technique is a powerful tool for detecting single nucleotide DNA mutation compared to the PCR technique. SERS technique is based on the amplification of the signal of the Raman marker using plasmonic NPs. In PCR, the amplification is carried out for the samples, which consume time and are complicated. This procedure is not dedicated to KRAS gene mutation only but could as well be applied to differentiate between mutated DNA and normal DNA for any type of cancer.

\section{Acknowledgments}

The generous support of the Egyptian STDF grant ID 4929 is greatly appreciated. The author(s) thanks to Dr. Reham Hassan for helpful support and discussions.

\section{Declaration of Conflicting Interests}

The author(s) declared no potential conflicts of interest concerning the research, authorship, and/or publication of this article. 


\section{References:}

1. Watson, J. D., \&amp; Crick, F. H., The Structure of DNA. Cold Spring Harbor Symposia on Quantitative Biology, 18, 123-131. https://doi.org/10.1101/sqb.1953.018.01.020

2. Liu, A., Wang, K., Weng, S., Lei, Y., Lin, et al. (2012). Development of electrochemical DNA biosensors. TrAC Trends in Analytical Chemistry, 37 (1953) 101-111. https://doi.org/10.1016/j.trac.2012.03.008

3. Xu, X., Weng, X., Liu, A., Lin, Q., Wang, C., Chen, W., \&amp; Lin, X., Electrochemical genosensor for detection of human mammaglobin in polymerase chain reaction amplification products of breast cancer patients. Analytical and Bioanalytical Chemistry, 405(10) (2013) 3097-3103. https://doi.org/10.1007/s00216-013-6715-6

4. Ray, A., \&amp; Nordén, B., Peptide nucleic acid (PNA): its medical and biotechnical applications and promise for the future. The FASEB Journal, 14(9) (2000) 1041-1060. https://doi.org/10.1096/fasebj.14.9.1041

5. Shekhawat, S. S., Gaurav, A., Joseph, B., Kumar, H., \&amp; Kumar, N., Random amplified polymorphic DNA-based molecular heterogeneity analysis of Salmonella enterica isolates from foods of animal origin. Veterinary World, 12(1) (2019) 146-154. https://doi.org/10.14202/vetworld.2019.146-154

6. Dobhal, S., Zhang, G., Rohla, C., Smith, M. W., \&amp; Ma, L. M., A simple, rapid, costeffective, and sensitive method for detecting Salmonella in environmental and pecan samples. Journal of Applied Microbiology, 117(4) (2014) 1181-1190. https://doi.org/10.1111/jam.12583

7. Liu, Z. J., Li, P., Argue, B. J., \&amp; Dunham, R. A., Random amplified polymorphic DNA markers: usefulness for gene mapping and analysis of genetic variation of catfish. Aquaculture, 174(1-2) (1999) 59-68. https://doi.org/10.1016/s0044-8486(99)00007-1

8. Jancik, S., Drabek, J., Berkovcova, J., Xu, Y., Stankova, M., et al., A comparison of Direct sequencing, Pyrosequencing, High resolution melting analysis, TheraScreen DxS, and the K-ras StripAssay for detecting KRAS mutations in non-small cell lung carcinomas. Journal of Experimental \&amp; Clinical Cancer Research, 31(1) (2012) 79. https://doi.org/10.1186/1756-9966-31-79

9. Kobunai, T., Watanabe, T., Yamamoto, Y., \&amp; Eshima, K., The frequency of KRAS mutation detection in human colon carcinoma is influenced by the sensitivity of assay methodology: A comparison between direct sequencing and real-time PCR. Biochemical and Biophysical Research Communications, 395(1) (2010) 158-162. https://doi.org/10.1016/j.bbrc.2010.03.167

10. Liu, P., Fang, X., Feng, Z., Guo, Y.-M., et al., Direct Sequencing and Characterization of a Clinical Isolate of Epstein-Barr Virus from Nasopharyngeal Carcinoma Tissue by Using Next-Generation Sequencing Technology. Journal of Virology, 85(21) (2011) 11291-11299. https://doi.org/10.1128/jvi.00823-11

11. Sloan, D. B., Warren, J. M., Williams, A. M., Wu, Z., Abdel-Ghany, S. E., Chicco, A. J., \&amp; Havird, J. C., Cytonuclear integration and co-evolution. Nature Reviews Genetics, 19(10) (2018) 635-648. https://doi.org/10.1038/s41576-018-0035-9

12. Moskovits, M, Surface-enhanced spectroscopy. Reviews of Modern Physics, 57(3) (1985) 783-826. https://doi.org/10.1103/revmodphys.57.783

13. Hassan, H., Abdallah, T., Negm, S., \& Talaat, H., Rabi like angular splitting in surface plasmon polariton - exciton interaction in ATR configuration. Applied Surface Science, 441(2018) 341-346. https://doi.org/10.1016/j.apsusc.2018.02.020 
14. Guerrini, L., \&amp; Alvarez-Puebla, R. A., Surface-Enhanced Raman Spectroscopy in Cancer Diagnosis, Prognosis and Monitoring. Cancers, 11(6) (2019) 748. https://doi.org/10.3390/cancers11060748

15. Barhoumi, A., \&amp; Halas, N. J., Label-Free Detection of DNA Hybridization Using Surface Enhanced Raman Spectroscopy. Journal of the American Chemical Society, 132(37) (2010) 12792-12793. https://doi.org/10.1021/ja105678z

16. Huh, Y. S., Chung, A. J., \&amp; Erickson, D., Surface enhanced Raman spectroscopy and its application to molecular and cellular analysis. Microfluidics and Nanofluidics, 6(3) (2009) 285-297. https://doi.org/10.1007/s10404-008-0392-3

17. Xu, L.-J., Lei, Z.-C., Li, J., Zong, C., Yang, C. J., and Ren, B., Label-Free SurfaceEnhanced Raman Spectroscopy Detection of DNA with Single-Base Sensitivity. Journal of the American Chemical Society, 137(15) (2015) 5149-5154. https://doi.org/10.1021/jacs.5b01426

18. Awad, H. Waly, N. Abdallah, T. Negm, S. and Talaat H., Study of Label-Free Detection and Surface Enhanced Raman Spectroscopy (SERS) of Fibrinogen Using Arrays of Dielectric Core-Metal Nanoparticle Shell. Journal of Analytical and Bioanalytical Techniques, S13 (2015) 010-014. https://doi.org/10.4172/2155-9872.s13-010

19. Elgendy, A. T. and Abdallah, T., Cancer therapy system based on gold nanoparticle / cold plasma via stimulated singlet oxygen production Journal of Physics: Conference Series, 1253 (2019) 012003 https://doi.org/10.1088/1742-6596/1253/1/012003

20. Awad, H., Abdallah, T., Negm, S., \& Talaat, H., Size effect of gold nanospheres on the photoacoustic imaging of cancerous cells. IOP Conference Series: Materials Science and Engineering, 762(1) (2020) 012004. https://doi.org/10.1088/1757-899x/762/1/012004

21. Wu, L., Garrido-Maestu, A., Guerreiro, J. R., Carvalho, S., Abalde-Cela, S., Prado, M., \&amp; Diéguez, L., Amplification-free SERS analysis of DNA mutation in cancer cells with single-base sensitivity. Nanoscale, 11(16) (2019) 7781-7789. https://doi.org/10.1039/c9nr00501c

22. Wu, L., Teixeira, A., Garrido-Maestu, A., Muinelo-Romay, et al., Profiling DNA mutation patterns by SERS fingerprinting for supervised cancer classification. Biosensors and Bioelectronics, 165 (2020) 112392. https://doi.org/10.1016/j.bios.2020.112392

23. Dukes, P. V., Strobbia, P., Ngo, H. T., Odion, R. A., Rocke, D., Lee, W. T., \&amp; VoDinh, T., Plasmonic assay for amplification-free cancer biomarkers detection in clinical tissue samples. Analytica Chimica Acta, 1139 (2020) 111-118. https://doi.org/10.1016/j.aca.2020.09.003

24. Hayward, S. L., Lund, P. E., Kang, Q., Johnson-Buck, A., Tewari, M., \&amp; Walter, N. G., Ultraspecific and Amplification-Free Quantification of Mutant DNA by SingleMolecule Kinetic Fingerprinting. Journal of the American Chemical Society, 140(37) (2018) 11755-11762. https://doi.org/10.1021/jacs.8b06685

25. Li, Y., Gao, T., Xu, G., Xiang, X., Zhao, B., Han, X. X., \&amp; Guo, X., Direct Approach toward Label-Free DNA Detection by Surface-Enhanced Raman Spectroscopy: Discrimination of a Single-Base Mutation in 50 Base-Paired Double Helixes. Analytical Chemistry, 91(13) (2019) 7980-7984. https://doi.org/10.1021/acs.analchem.9b01887

26. Pyrak, E., Krajczewski, J., Kowalik, A., Kudelski, A., and Jaworska, A., Surface Enhanced Raman Spectroscopy for DNA Biosensors-How Far Are We? Molecules, 24(24) (2019) 4423. https://doi.org/10.3390/molecules24244423

27. Swinehart, D. F. The Beer-Lambert Law., Journal of Chemical Education, 39(7) (1962) 333. https://doi.org/10.1021/ed039p333

28. Zielińska, A., Skwarek, E., Zaleska, A., Gazda, M., \&amp; Hupka, J., Preparation of silver nanoparticles with controlled particle size. Procedia Chemistry, 1(2) (2009) 15601566. https://doi.org/10.1016/j.proche.2009.11.004

29. Desireddy, A., Conn, B. E., Guo, J., Yoon, et al. Ultrastable silver nanoparticles. Nature, 501(7467) (2013) 399-402. https://doi.org/10.1038/nature12523 
30. Mulfinger, L., Solomon, S. D., Bahadory, M., Jeyarajasingam, A. V., Rutkowsky, S. A., \&amp; Boritz, C., Synthesis and Study of Silver Nanoparticles. Journal of Chemical Education, 84(2) (2007) 322. https://doi.org/10.1021/ed084p322

31. Brunetti B, D. E. About Estimating the Limit of Detection by the Signal to Noise Approach. Pharmaceutica Analytica Acta, 06(04) (2015) https://doi.org/10.4172/21532435.1000355

32. Kann, B., Offerhaus, H. L., Windbergs, M., \&amp; Otto, C., Raman microscopy for cellular investigations - From single cell imaging to drug carrier uptake visualization. $\begin{array}{lllll}\text { Advanced Drug Delivery } & \text { Reviews, } 89 & \text { (2015) 71-90. }\end{array}$ https://doi.org/10.1016/j.addr.2015.02.006

33. Palonpon, A. F., Sodeoka, M., \&amp; Fujita, K. Molecular imaging of live cells by Raman microscopy. Current Opinion in Chemical Biology, 17(4) (2013) 708-715. https://doi.org/10.1016/j.cbpa.2013.05.021

34. Han, X. X., Zhao, B., \&amp; Ozaki, Y., Surface-enhanced Raman scattering for protein detection. Analytical and Bioanalytical Chemistry, 394(7) (2009) 1719-1727. https://doi.org/10.1007/s00216-009-2702-3

35. Xu, L.-J., Zong, C., Zheng, X.-S., Hu, P., Feng, J.-M., \&amp; Ren, B., Label-Free Detection of Native Proteins by Surface-Enhanced Raman Spectroscopy Using IodideModified Nanoparticles. Analytical Chemistry, 86(4) (2014) 2238-2245. https://doi.org/10.1021/ac403974 